https://helda.helsinki.fi

Changes in the sense of agency: Implications for the psychotherapy of bulimia nervosa- A case study

Kristmannsdottir, Gudrun

2019-08

Kristmannsdottir , G , Keski-Rahkonen , A \& Kuusinen, K-L 2019 , ' Changes in the sense of agency : Implications for the psychotherapy of bulimia nervosa- A case study ', Journal of Clinical Psychology , vol. 75 , no. 8 , pp. 1415-1428 . https://doi.org/10.1002/jclp.22787

http://hdl.handle.net/10138/312913

https://doi.org/10.1002/jclp.22787

draft

Downloaded from Helda, University of Helsinki institutional repository.

This is an electronic reprint of the original article.

This reprint may differ from the original in pagination and typographic detail.

Please cite the original version. 


\title{
Changes in the sense of agency: Implications for the psychotherapy of bulimia nervosa- A case study
}

\author{
Gudrun Kristmannsdottir $^{1}$ | Anna Keski-Rahkonen ${ }^{2}$ | \\ Kirsti-Liisa Kuusinen ${ }^{3}$
}

${ }^{1}$ Private Practice, Helsinki, Finland

${ }^{2}$ Department of Public Health, University of Helsinki, Helsinki, Finland

${ }^{3}$ Department of Psychology, University of Jyväskylä, Jyväskylä, Finland

\section{Correspondence}

Gudrun Kristmannsdottir, Advanced

Specialist Level Psychotherapist,

Döbelninkatu 2, 00260 Helsinki, Finland.

Email: kristmannsdottir@liikkuvamieli.com

\begin{abstract}
A sense of agency is a transtheoretical concept that increases our understanding of important processes in psychotherapy. Agency can be described in terms of how strongly the person believes that she can have an impact on her problematic experiences and behaviors. In this case study, a patient's sense of agency in relation to symptoms of bulimia nervosa was assessed during 3 years of psychotherapy. Five distinct phases of agency in relation to eating disorder symptoms were identified: A false sense of agency or no agency at all, a weak sense of agency, a nascent sense of agency, a wavering sense of agency, and a strong sense of agency. A better understanding of patient agency can facilitate adapting approaches and methods best suited for the patient's capacity for change throughout treatment.

KEYWORDS

agency, bulimia nervosa, eating disorder, psychotherapy
\end{abstract}

\section{1 | INTRODUCTION}

Eating disorders are sets of behaviors and thought processes that can cause severe suffering and have a profound impact on a person's life. Although many different psychotherapeutic approaches have been developed for eating disorders, recent meta-analyses have shown that no one treatment model succeeds better than others (Linardon, Fairburn, Fitzsimmons-Craft, Wilfley, \& Brennan, 2017; Steinert, Munder, Rabung, Hoyer \& Leichsenring, 2017).

There is no clear consensus in the field whether the psychotherapeutic treatment of eating disorders should focus on eating behaviors or their underlying emotions and psychological processes. Fasting and dietary restraints have shown to be behaviors that maintain bulimic eating pathology (Stice, Davis, Miller, \& Marti, 2008). Starvation 
in itself may also influence cognitions, emotions, and physical experiences; these effects might be explained by changes in the adaptive reward system in the human brain in response to extremes of food intake (Frank, 2015). It has also been demonstrated that there are other underlying cognitive and emotional processes that maintain bulimia nervosa; these include the pursuit of thinness and judging of self-worth in terms of weight and shape (Fairburn et al., 2003).

Physiological, starvation-related changes likely affect the psychotherapy process in many important ways. Because the aim of psychotherapy is usually to work with maladaptive emotions, cognitions, and underlying psychological issues, starvation-related physiological changes are often overlooked. In medical treatment settings, the opposite is often true: when the main focus is on eating disorder symptoms, behaviors, and nutrition, underlying thoughts and emotions are often overlooked. Treasure, Stein, and Maguire (2015) formulated a stage model of eating disorder pathology based on the evidence of neurobiological progression resulting from long term malnutrition. They suggested that interventions should match the different stages of eating disorder to optimize the benefits of treatment. Similarly, Treasure, Cardi, Leppanen and Turton (2015) suggested a "stepped care protocol" (p. 462) in the treatment of eating disorders, contending that therapeutic approaches should be implemented according to the patient's physiological status and psychological capacity. They recommended that treatment with change-resistant patients should be modified to target the dysregulated thought and behavior patterns that maintain the disorder.

Hilde Bruch (1974) was a pioneer in developing a psychological treatment for eating disorders. She argued that eating disorders are caused by a deficiency in the sense of self, which results in a lack of important mental processing capacities. Skårderud and Fonagy (2012), building on the Bruch's theory, have conceptualized the core problem in eating disorders as deficiencies in the patient's mentalization ability-a term that refers to individuals' ability to understand their own and others' behaviors in terms of "action of the mind" (Fonagy \& Bateman, 2012). When a person's capacity to mentalize is good enough, she understands that her own thoughts and feelings are created by her own mind. She understands that her thoughts and feelings will not necessarily be an accurate reflection of the external world or other people's experiences. She also understands that others' actions can be comprehended in terms of happenings and content of their own mind.

The capacity for mentalization is thought to be a prerequisite for a sufficient sense of agency in relation to emotions and behavior (Fonagy \& Target, 1997); the experience of agency is thought to be a marker of adequate mentalizing capacity (Allen \& Fonagy, 2008). The psychological agency has been defined as an ability to experience thoughts, emotions ("events" in the mind), and behaviors as belonging to the self and as being under the influence and control of the self (Kögler, 2010; William \& Lewitt, 2007). In terms of symptoms, the agency can be described as how strongly the person believes that she can have an impact on her problematic experiences and behaviors. In addition to mentalization, the concept of agency appears to be related to several other theoretical models, including Eysenck's locus of control (Hope, Wakefield, Northey, \& Chapman, 2018), Bandura's conceptualization of self-efficacy (Bandura, 1977), and Prochaska and DiClemente (1982) transtheoretical model that includes suggestions for therapeutic work matched to clients' different motivational stages ("Stages of Change").

Enhancing the client's agency is a key goal across multiple psychotherapeutic traditions; however, research has produced little empirical direction on how to strengthen the sense of agency during psychotherapy (William \& Lewitt, 2007). Therapists from different psychotherapy traditions may have distinct ways of defining and understanding the role of agency within the process of therapeutic change (Williams \& Levitt, 2007). Nevertheless, several common principles across orientations can be identified and be useful in guiding therapists to facilitate increases in patients' psychological agency. Key principles include enhancing the patient's self-awareness and exploring those aspects of a patient's life that can or cannot be changed.

The concept of an agency may be especially complicated in the context of eating disorders. Among many others, Bruch (1974) pointed out that a person suffering from an eating disorder often experiences the symptoms as a perfect solution to her problems. In such situations, although the psychological agency is actually weak, the patient 
maintains a false but strong sense of agency. Eating disorder symptoms may protect individuals from developmental pressures and feelings of inferiority (Vitousek \& Ewald, 1993).

Along these lines, Gullestad and Wilberg (2011) described a case of a patient with an eating disorder and comorbid borderline personality disorder whose reflective functioning (a manifestation of her ability to mentalize) was strengthened in the course of long-term psychotherapy but whose level of symptomatology did not concomitantly decrease as expected. This might suggest that there are intervening factors between the development of mentalization and the strengthening of the one's sense of agency, factors that need to be taken into consideration in the treatment of eating disorder patients.

The interplay of psychological and physiological factors is also an element that makes the concept of the agency more complex in eating disorders than in most other psychiatric disorders. Although eating disorders are usually seen as psychiatric (i.e., medical) disorders, there are unambiguous psychological effects of the chaotic eating behavior or starvation on the person's mind and behavior. When a patient comes into treatment, she is expected to be able to change her eating and exercise behaviors and cognitions, given sufficient motivation. Thus, her sense of agency in relation to the symptoms is expected to be sufficient. She is expected to be able to make choices about changing eating behavior if she wants it strongly enough. However, given that eating disorders stem from the interplay of psychological and physiological factors, there is a possibility that the patient's sense of agency is not strong enough for clear decision-making.

In the field of eating disorder research and treatment, the patient's readiness for treatment is often assessed by his or her level of motivation to change (Prochaska \& DiClemente, 1982). Motivational interviewing has been shown to facilitate behavior change in eating disorders (Treasure \& Schmidt, 2001). The problem with assessing the patient's readiness to change is that it does not take sufficiently into consideration the painful emotions (e.g., fear, shame, and anxiety) that are possible barriers to change. Assessing readiness to change also does not take into account the interplay of starvation-related physiological and psychological factors and their impact on the patient's ability to feel motivated, and to think clearly, intentionally, and flexibly.

One of the most important tenets of motivational interviewing is that the patient is able to decide to change things if she is motivated enough; however, in eating disorders, this freedom of choice might be restricted as a part of the illness process (Treasure \& Schmidt, 2008). For example, poor reflective functioning and an informational processing style that is over-occupied with small details are characteristic of eating disorder patients and may interfere with adequate motivation.

In terms of eating disorder symptoms, the sense of agency can be considered weak when the patient feels that she is helpless or "attacked" by emotions, thoughts, and behavioral symptoms related to the eating disorder. When the patient's sense of agency gradually becomes stronger, she can relate to her problems in a new way, and see alternatives and options that are under her control. At that stage, she can believe that she is able to change her behavior if she has the intention and a motivation to do so. From this perspective, the concept of motivation can only be used to describe the patient's readiness for change when she has a sufficient sense of agency.

Could assessing the sense of agency be a useful tool in tailoring the treatment for eating disorders and compulsive exercise? To explore that question, the senior author of this paper (GK), assessed and defined a patient's sense of agency in relation to eating disorder symptoms in the process of 3 years of psychotherapy.

The research was carried out as a phenomenological, descriptive, and qualitative study (Barker, Pistrang \& Elliott, 2002). The level of the agency at different phases of therapy was assessed by analyzing the patient's verbal expressions and attitudes related to the eating disorder symptoms throughout the therapy process. The hypothesis of this study was that careful listening to a patient's reflections about eating disorder symptoms and emotions related to them in different phases in therapy allows us to understand better the ways in which she develops her capacity for reflection and change in symptomatic behavior and thinking. 


\section{2 | CASE ILLUSTRATION}

\subsection{Problems and client description}

The subject of this case study was a 30-year-old woman, Katie (a pseudonym), who sought psychotherapy for longlasting eating disorder symptoms and compulsive exercise. She came from a highly educated family. Her older brother had suffered from serious depression from adolescence. Their mother was career-oriented and returned to work when the patient was four months old. A nanny came to the house and took care of Katie and her brother while the parents were working. Throughout Katie's childhood, her parents worked long days.

The father was, emotionally, a rather distant figure in Katie's life, although he was always ready to help her with practical things. Katie remembered that as a little girl, she often waited anxiously in her bed for her mother to come home from work, especially when she (mother) worked late. A central experience in her mind from early on was that she was not good enough to be accepted and loved and that she should somehow be different.

In the beginning of therapy, Katie recalled that by age 10 she already had a desire to lose weight. In early adolescence, she felt bit "chubby"-she was within the normal weight range but was tall-and she received some negative comments from schoolmates about her appearance. She began dieting at the age of 14 and suffered from anorexia nervosa symptoms for about 3 years. She was underweight, but "not enough" to being paid attention to by family members, school professionals, or friends. She got positive feedback from family and friends for the weight loss and became afraid of losing control over her eating. Katie also felt that her mother was critical of overweight people and got the impression that overweight people were somehow less worthy. To be successful in life, she felt she had to be thin and fit. She also remembered that her mother's relationship with food was problematic. She had been on a diet as long as Katie remembered and seldom ate with the rest of the family.

At the age of 17, Katie developed binge/purge symptoms, and she suffered from these symptoms until seeking psychotherapy at the age of 30 . In between, she went through restrictive phases and was often at the edge of being underweight. In addition to purging as a means of compensation, she exercised compulsively every day. Compulsive exercise became an important issue to work on in the course of psychotherapy.

When Katie came to therapy, she had been married for a few years and had a 3-year-old child. Just before starting therapy, she had told her husband about her eating disorder. This was a big step for her, as she was very ashamed of her symptoms. If there were any arguments or difficulties in the marital relationship, her eating disorder symptoms usually increased.

\section{2 | Case formulation}

From a very early age, Katie had the experience of being the "wrong kind" and not worth loving. Despite having many happy memories of childhood, she thought that something must be wrong with her because she was suffering from a negative self-image and an eating disorder. Katie was struggling with the deeper conflict of never feeling special or important enough for her mother.

Katie saw her mother as a very strong and tough woman, and even as a little girl she wanted to be like her. She felt that she would get approval if she had these same qualities; if not, she feared being abandoned by her mother as well as by others. This feeling followed her into adulthood. It became obvious that Katie felt she had to hide any signs of weakness and vulnerability from very early on, and that she had not learned to deal with negative and vulnerable feelings in an adaptive or effective way. The experience of "being the wrong kind" concretized in Katie's life as "being the wrong size". This, she thought, she should fix. She felt that being as thin as possible would compensate for the feeling of not being good enough. By being thin, her longing for acceptance would be fulfilled.

In moments of feeling weak, scared, and vulnerable, she felt extremely alone, but could not reach out to others for comfort and help. In these moments of despair, her eating disorder symptoms seemed to assume the role of the "comforter". Katie felt that eating disorder symptoms were hindering her from living a full life, but at the same time, 
repetition of the destructive but familiar behaviors gave her a feeling of security and "a way out" from experiencing difficult emotions. That is, when experiencing negative feelings, Katie reacted by binging and/or purging without being able to influence these behaviors in any way. Her sense of agency in relation to her eating disorder symptoms was very low. It was obvious from the beginning of therapy that Katie had difficulty in feeling any compassion for herself, instead of relating to herself with a hostile and unrealistic demanding attitude.

\section{3 | Course of treatment}

The therapy was carried out by an experienced integrative psychotherapist (GK), who had training in integrative psychotherapy (Boswell, Nelson, Nordberg, McNeavey, \& Castonguay, 2010: Markin, 2014) and mentalizationbased therapy for eating disorders (Skårderud \& Fonagy, 2012). The therapist's frame of reference in understanding the patient's psychological processes was based on psychodynamic developmental theory, mentalization-based theory (attachment theory), and cognitive-behavioral theory, with special emphasis on the therapeutic relationship. The therapist used elements from mentalization-based theory and cognitive-behavioral theory when working with psychoeducational themes. She also assigned special tasks and homework related to behavioral symptoms.

\section{4 | Brief overview of the treatment process}

Katie appeared to go through five phases of agency in relation to her eating disorder symptoms throughout the therapy process (see discussion below). However, the process did not proceed smoothly from one phase to the next. Rather, it proceeded forward and then backward and eventually forward again. Notably, there seemed to be different kinds of emotional themes rising to the surface in the different phases of her sense of agency, each appearing to need special attention during these 3 years of psychotherapy.

In the beginning of therapy, Katie s sense was that she had no reliable control over her eating behavior. She tried to restrict her eating as much as possible, which eventually resulted in uncontrollable binging episodes that often lasted many days. Although the reason for binging and purging seemed mainly to be due to previous fasting periods, she interpreted the behavior as "lack of self-control". Her way of thinking about herself, her body, and her eating behavior were rigid. Thus, the physiological effects of the chaotic eating behavior were reinforcing Katie's experience of not being in control of her emotions and behaviors. In the last year of therapy, Katie's sense of agency in relation to the eating disorder symptoms had clearly been strengthened, and she felt that she had choices in relation to them. This allowed for flexibility, or in other words, "a space in her mind", to face deeper emotional issues in her life.

In the beginning of therapy, strong emotions seemed to exist for Katie only in relation to her symptoms (a "safe place" to contain difficult emotions). For example, fear was related to gaining weight, anger was related to not being able to control herself, and shame was related to the feeling of being the wrong size. Later in therapy, with a strengthened sense of agency and feeling of security in her relation to her therapist, Katie's understanding of her emotions became deeper and were no longer related only to her eating disorder symptoms and body size.

In the last 6 months of therapy, Katie had occasional thoughts related to her eating disorder, but she was no longer acting on them. Instead, she could choose more adaptive means of emotion regulation. She was also at peace with the eating disorder on an emotional level when the therapy ended. That meant that she could understand and accept occasional eating related thoughts and could relate to herself with compassion and understanding. She began to appreciate that her eating disorder had been a psychological solution to situations when she could not find another means of emotional regulation, a solution that actually might have helped her through intolerable experiences.

The next section is a description of the five phases of agency identified in the present case study. 


\section{5 | Phase 1. A sense of false agency/no sense of agency: -"It just happens to me, I can't do anything about it"}

When Katie came to therapy, she felt strongly like a victim of her eating disorder symptoms. She regarded her binging and purging as her main symptoms, with fasting and compulsive exercise seen as a means of compensating. She experienced her symptoms as developing without her having any options or choices; thus, her experienced agency in relation to the symptoms appeared to be very low. She tried to take control of her bingeing and purging by restricting her eating, even more, attaining in a way a sense of "false agency". However, those seemingly "under control" phases lasted but a short time, only to trigger new bingeing and purging episodes. In the beginning of therapy, Katie also had the illusion of being in control during her fasting phases, an illusion that dissipated when binging episodes inevitably re-emerged as the result of the fasting period. The emotional theme in this phase of the agency was primarily helplessness, including feelings of being unable to control her own mind and behavior. That, in turn, caused feelings of shame and incompetence that appeared to be barriers to change.

In discussions about her eating disorder symptoms, phrases such as "had to" or "forced to" appeared in Katie's narrative, implying the feeling of having no choice at all, that symptoms strike her "from the outside", and that she cannot do anything about them. The underlined statements in Katie's comments below illustrate how a weak sense of agency characterizes her talk about her eating disorder:

Session 2: "I ate far too much at work, I had to purge when I came home"

Session 5:"I felt so bad, I was forced to binge, don't know why"

Session 8: "Purging was indispensable, I had eaten too much, that was the only solution".

Session 11: "I was suddenly in the shop buying food to binge, I don't even remember what I bought"

Session13: "I've eaten more this week, I must exercise a lot more"

Session 17:"If I allow myself to eat, I'll continue and continue, and I'm not able to stop"

The emotional themes of incompetence, helplessness, and shame required special attention during the early phase of therapy because they affected her beliefs that therapy could not help her in any way. These themes seemed to "live and grow" around the eating disorder experiences. Psychoeducation was a very important part of the therapeutic process in this phase of the therapy, given the eating behavior's influence on Katie's psychological experience. Although Katie partly resisted accepting the psychoeducational information and the fact that, at least in part, her symptoms were related to her eating behavior (physiological effects), the psychoeducational discussions provided her a sense of safety and facilitated some self-compassion.

\section{6 | Phase 2: "A weak sense of agency -"Reason says, but I can't..."}

After about half a year into therapy, Katie's understanding of how her eating habits, exercise behavior, and negative self-talk were functioning as barriers to change in her life increased. But her frustration and fear intensified when she recognized the possibilities and the hope of being able to change but felt she could not do anything differently on a behavioral level. She was afraid that if she changed her behavior, everything would fall apart-in this phase of therapy, the fear was focused mainly on gaining weight. Included in that experience was also the fear that her weakness and vulnerability would become visible to other people. A move to the unknown (i.e., changes in behavior) felt too dangerous. 
When discussing the thoughts related to eating and behavior, more distinctive and clearer reflections about the eating disorder occasionally appeared in Katie's talk, although her experiences (cognitions, emotions) were at the same time mostly black and white (dichotomous). She focused on experiences of failures and ignored experiences of success. In this context, success means being able to make choices about thoughts related to eating, emotions, and behaviors.

The underlined statements in the descriptions below illustrate markers of black and white thoughts and difficulties with self-reflection in relation to the eating disorder:

Session 25: "I failed again. I binged an awful lot on Tuesday, I had to fast on Wednesday. Although I knew that I would binge again over the weekend"

Session 27:"I' different from other people. If I eat sweets, I immediately get fat. Everybody else can eat what they want. I know this is a stupid thought, but I can't change it"

Session 31:"There are good days when I eat little and bad days when I eat too much"

Session 32:"I've no self-discipline, I have food on my mind all the time"

Session 34:"If I'm not thin, I might accidentally end up as an overweight person"

The significance of the psychoeducational elements in the therapy process seemed to become even stronger in this phase of her sense of agency. The therapist's continuous reminder of how nutrition and compensatory behaviors influence her mind seemed to help her reflect on the possibility of change in eating behavior outside of therapy. On the other hand, Katie's suffering increased in this phase of experience because she understood the multilevel influence of her eating behavior on maintaining the eating disorder. Her level of the agency was still weak, and she felt hopeless and trapped. Emotions like fear and anger (toward herself) and the conflict between hope and hopelessness were central to her experience in this phase of agency. Nonetheless, she had developed some insight to the influence of here behaviors on her eating disorders, and at times had some doubts about her inability to change.

\section{7 | Phase 3: A nascent sense of agency -"Sometimes I succeed, but I often fail"}

After about 1 year in therapy, a new level of agency appeared in Katie's experience and she seemed to be at a critical point in relation to her eating disorder symptoms. She understood, both in a more concrete and profound way, that her symptoms might have deeper emotional relevance in her life. She found more distinctive connections between experiences and emotions and saw that they might be understood in the context of her life history. She reflected more intensely on the thoughts related to her eating disorder and questioned them. She also distinguished, identified, and reflected more often on her emotional experiences, and she used complex phrases when describing them.

Her developing capacity for understanding her own mind and the eating disorder's function in a more complex way allowed Katie to now understand that the chaotic eating behavior and compensations (purging, excessive exercise) were maintaining her symptoms. She took risks more often, challenged the compulsive thoughts, and was more often symptom free than before. The belief that she herself could have an impact on her behavior became stronger. But she still sometimes "let herself go", without fighting, relapsing into eating disorder symptoms, because it felt like an easy and safe way to survive emotional turmoil. Thus, her level of agency in relation to her eating disorder symptoms had clearly been strengthened but was still inadequate. Emotions like self-loathing, disappointment, and emptiness, along with occasional acceptance, were central to her experience during this 
phase of agency. Nonetheless, she was able to at this stage to question the emotional meaning of her symptomsunderstanding them as a means to survive emotional turmoil, and also able to increasingly challenge them.

Examples below illustrate a strengthening of her sense of agency and the underlined statements illustrate markers of conflicted thoughts and emotions:

Session 38: "I knew I would binge, because l'd got that feeling. I ate normally earlier in the day, because I tried to resist bingeing, but I lost the control in the evening"

Session 39: "I said to myself that everything is all right, that l've eaten normally. Session 41:" Regular eating is good for me. I didn't purge. Then [that thought] worked, but not anymore last night. Maybe Saturday was just a good day or something. [In the beginning of this narrative, she's experiencing some sense of agency. In the end, it seems to be lost]

Session 41:"Hunger is a good and safe feeling, then I know for sure that l've not eaten too much

Session 42:"I was full, I couldn't stand the feeling, I had to purge

Session 44:"Immediately when there is a conflict, I escape to the symptoms"

Session 45: "This will never end, I purged again on Sunday after I' eaten pizza, I couldn't stand it. I'm hopeless, I don't have any self-discipline"

Session 46: "I 'm stressed, I have skipped meals".

Session 46: "Why try, when I fail anyway?"

As can be seen in the examples above, when compared to phase two of the agency, Katie had now started relating to the thoughts of her eating disorder and behavior more like "happenings inside the mind" than something that happens outside of her and out of her control. These moments appeared irregularly at first and sometimes she could not capture at all that aspect of "things happening in the mind". Then she experienced the urge to binge or fast as invading from the outside without her being able to control her behavior. However, Katie could feel the frustration, because her way of thinking about eating, food, and exercise was changing in a more flexible direction. On an emotional level, she was still afraid of change and of losing control-that is, of losing partly achieved agency in relation to the symptoms and becoming overweight without noticing it.

On the other hand, compassion and self-acceptance were more often noticeable in her talk about her eating disorder symptoms. That was an important turning point in therapy because the developing ability to feel selfcompassion became an essential "working tool" in her struggle with the eating disorder in therapy, offering her a new self-perspective.

The therapist endeavored to help Katie grasp these preliminary experiences of acceptance and compassion and to use them in the fight against the urge to binge and fast. Katie also seemed to need a great deal of encouragement and support when her sense of agency was weak and self-loathing thoughts predominated once again; importantly, though, she was able to express that need little by little. However, most of the time Katie focused on experiences of failure and incompetence, times when she was not able to stand up to the symptoms. She needed the therapist to remind her and help her to "refocus" on moments when the experience of the agency had been stronger and she felt that she had choices.

Psychoeducation was an essential element in this phase of her sense of agency and was a natural part of the therapy process. Because Katie was in a new "place in her mind" where she was able to look in both directions--life 
with an eating disorder and life without it--she felt she needed the prod from the therapist to be able to resist the urge and temptation to "go back" into the eating disorder as it was before. The therapist's continual small doses of psychoeducational information that she "smuggled" into the conversation within every session appeared to function as a safe element for Katie to keep in mind and reflect on between the sessions.

\section{8 | Phase 4: A wavering sense of agency -"I usually have a choice, but sometimes I make wrong choices"}

In the second half of the second year of therapy, Katie appeared to reach the fourth phase of agency, partial mastery overeating disorder symptoms. When she resorted to the symptoms, she felt like it was more of a choice (a strong sense of agency) rather than that she was forced to resort to them (weak agency), as in earlier phases of experience. She was able to eat relatively regularly and sufficiently, and the occasional experience of" losing control" was no longer resulting in long periods with increased symptomatic behavior. Feeling that she was"letting go" and a sense of mourning was central to her experience.

Katie felt insecure and psychologically lonely without the symptoms, although they had caused her pain and misery. She was often sad and felt that she had changed and her mind had changed, but the result was the loss of a feeling of security. She could not go back to "the safe place" that the eating disorder symptoms had offered her; as she put it, "I can't do it anymore". Later, she was able to go deeper into the emotional theme of mourning and was grieving everything she had lost in life because of the eating disorder. She understood the protective function of the eating disorder and was able to find the little vulnerable girl inside her, get in touch with her, and feel compassion for her.

The underlined statements below illustrate a strengthened sense of agency in Katie's talk about her eating disorder:

Session 52: "I'm kinder to myself. If I have some bad feeling, I try to stop and figure out what's going on inside me."

Session 53: "There are lots of good days. Now I feel that I have choices, at least sometimes."

Session 56: "I was afraid that I would get fat. I went to the bathroom and purged. I felt very bad afterwards"

Session 57: "The eating disorder symptoms are like a walking stick-- I use them because I feel weak"

Session 60: "I felt better when I told him [my husband] how I feel. I didn't feel the need to purge

Session 62: "I'm more gracious to myself. If I experience difficult feelings, I've tried to stay with them and explore them".

Session 62:"I know that the eating disorder is my safe place, I can always count on it."

Session 64: "I can't do it anymore, It's not the same [to stop eating as a way to control herself]

Session 66: "I 'm afraid of failing. What if I make wrong choices?"

Session 68: "I 've tried to think that the feeling is transitory, that it lasts only some time and then fades away." 
Session 70:" "f my opinions and feelings are so meaningless, I can stop eating. If I 'm irrelevant for him [my husband], I can hurt myself! If I hurt myself, I will hurt him, but is it worth it...?

Session 73: "There's nothing in life, nothing!" [giving up the symptoms evokes sadness, depressive thoughts and feeling of emptiness]

At the end of her second year in treatment, a sudden reversal in the development of Katie's sense of agency seemed to take place. Katie appeared to relapse to phase three in her sense of agency, feeling that she was failing more often than succeeding. The fear of losing a "safe place" in her mind and behavior (eating disorder) became prevalent. This reversion was understandable in light of the events in her life, but she had difficulties with understanding the connection. Shame, self-hatred, and disappointment reappeared as central themes.

After a few months of struggle and her therapist's continuous encouragement and validation of her experience, Katie managed to find her way back to a stronger sense of agency (phase 4). She also needed to be reminded of the influence of the eating disorder behaviors (fasting and binging) on her mind and body to be encouraged to be more accepting of herself. As a result, she regained the feeling of being able to choose between symptoms and no symptoms.

Prominent in this fourth phase was that the sense of agency in relation to the eating disorder symptoms had strengthened. Katie occasionally "used" the symptoms as a means to display emotions she struggled to openly express in close relationships (mainly in relation to her husband). If she got sad or angry, it felt safer to express the negative feelings in terms of symptoms: feeling angry and eating less-although her husband did not notice--or feeling sad and binge when her husband was not at home. In this phase, the symptoms seemed to be a conscious "quick fix" to get rid of negative emotions, and avoid having to risk conflicts in close relationships.

\section{9 | Phase 5: A strong sense of agency -"I can choose between different means of surviving painful emotions"}

In the last 6 months in therapy, Katie appeared to have achieved a new level of agency that enabled her to make real choices in relation to her eating disorder. In this fifth phase her sense of agency was now relatively strong, and Katie could trust herself in terms of not acting on the thoughts and emotions related to the eating disorder. On an emotional level, she understood the functions her symptoms had served in her life, and a clear feeling of selfcompassion had reached a new level.

Katie had now found various adaptive means to regulate her emotions when needed: reassuring self-talk, talking to family and friends about her experiences, mindfulness practice, yoga exercises, and the courage to tolerate negative feelings for longer periods. Feelings of hope, but also feelings of emptiness, were now central experiences in her mind.

The statements below illustrate Katie's strengthened ability to process eating disorder related thoughts and emotions in her mind:

Session 89:"I thought that I was horribly fat when I ate such an amount of food and it came into my mind that I could purge. However I knew that this feeling would go over if I wait a bit. And it did".

Session 93:"When it 's a bit difficult, it comes into my mind that I should lose weight. I know that by fasting, I get the feeling that I control my life. But that's not the real solution, I know that".

Session 95:"I 've noticed that always when I'm down, I start thinking about dieting. I know that fasting gives me a feeling of control. But that's not a solution to my problems...." 
Session 96:"Eating normally is not difficult anymore, and there are no extremes in my mind in the same way as before"

Session 104: "It came into my mind that I could lose weight when I got the feeling of being an outsider. I knew that it was my own fear, so I relaxed quite fast. And I won't try to lose weight!"

Although Katie did not experience behavioral eating disorder symptoms any longer, the thoughts related to eating disorder "invaded" her from time to time, especially when she had negative life experiences (e.g., in relationships or at work). Still, the eating disorder seemed to be near the surface and she felt that in a difficult situation she could easily resort to the behaviors. The difference compared to earlier phases was that she felt that resorting to these behaviors would be more of a choice rather than a feeling of losing control ("it happens to me"). Her agency in relation to the symptoms was thus clearly stronger than in the beginning of therapy.

\subsection{0 | Outcome and prognosis}

In the last year of therapy, Katie's experience fluctuated from phase four to phase five, depending on how things were going otherwise in her life (e.g., in regard to her marital relationship, work, and motherhood). When therapy ended, she was clearly at peace with the eating disorder thoughts and no longer afraid of them, but she was worried that she would turn back to the feeling of being the powerless receiver of the symptoms. Discussions in therapy were no longer focused on food, calories, or body size, but rather "happenings" inside her mind and experiences in relationships. The focus had shifted from the apparent symptoms of the eating disorder to the deeper, emotional meanings and underlying reasons for the disorder.

\subsection{1 | Clinical practice and summary}

The aim of this case study was to determine if there were distinctive phases of a sense of agency over the course of long-term therapy with a patient suffering from an eating disorder. The assumption was that by identifying the patient's sense of agency in different phases of therapy, the therapist could adjust her own approach accordingly, specifically in relation to the eating disorder symptoms and concomitant emotional themes.

In this case study, five distinct phases of the patient's sense of agency were identified. Each phase seemed to contain different emotional experiences in the course of 3 years of therapy. The study suggests that, based on the patient's current phase of the agency, the therapist should listen to and focus on somewhat different emotional themes and tasks, especially in relation to the eating disorder. By adjusting his or therapeutic methods in accord with the patient's capacities, the therapist can focus on and strengthen the patient's sense of agency. Table 1 offers some examples of therapeutic tasks that match each phase of an eating-disordered patient's sense of agency.

The psychological treatment of eating disorders is usually time-limited with a special focus on behavioral symptoms. Various short interventions offer the therapist a structure within which to work and useful methods to help the patient modify her eating disorder symptoms on a cognitive and behavioral level. The shortcoming of these approaches is that they leave open the question of how to continue the treatment when the behavioral symptoms have eased but painful emotional themes continue to surface as barriers to further progress.

It is essential to tailor the treatment for each patient-i.e., to find the appropriate approach according to the patient's psychological strengths and weaknesses (Treasure, Cardi, Leppanen \& Turton, 2015; Vitousek \& Watson, 1998). Understanding the primary phase of the agency of a patient at different points in therapy is a critical first step. e.g., if a patient's symptoms seem to be an uncontrollable reaction to physiological and/or emotional turmoilthat is, characteristic of phase one of agency (core feelings of fear, shame, and incompetence)--the patient needs a different clinical approach than in phase four, where he or she assumes partial agency in relation to eating-disorder symptoms but is "using" these symptoms as a tool of self-expression and communication of negative emotional 
TABLE 1 The five phases of patient agency and examples of corresponding therapeutic tasks

\begin{tabular}{|c|c|c|}
\hline Phase & Examples of Patient Statements & Therapeutic tasks \\
\hline \multirow[t]{2}{*}{$\begin{array}{l}\text { Phase 1: A false sense of } \\
\text { agency or no agency } \\
\text { at all }\end{array}$} & $\begin{array}{l}\text { - "I felt so bad, I was forced to binge, I don't } \\
\text { know why" }\end{array}$ & $\begin{array}{l}\text { - Validate the patient's experience of not } \\
\text { having control, that things "just happens"; } \\
\text { find the emotions related to that experience } \\
\text { and explore them. }\end{array}$ \\
\hline & & $\begin{array}{l}\text { - Offer psychoeducation about how the } \\
\text { dietary restraint contributes to the } \\
\text { experience of "it just happens to me" }\end{array}$ \\
\hline \multirow[t]{3}{*}{$\begin{array}{l}\text { Phase 2: A weak sense of } \\
\text { agency }\end{array}$} & $\begin{array}{l}\text { - "I failed again. I binged awfully much on } \\
\text { Tuesday, I had to fast on Wednesday". }\end{array}$ & $\begin{array}{l}\text { - Explore the patient's feeling of fear of } \\
\text { change and validate the experience. }\end{array}$ \\
\hline & & $\begin{array}{l}\text { - Bring the patient's attention to her own } \\
\text { "agency talk" ("now you said that you } \\
\text { decided to binge, and last time it kind of just } \\
\text { happened...tell me more about that")/ }\end{array}$ \\
\hline & & $\begin{array}{l}\text { - Encourage patient to take "risks" in eating } \\
\text { behavior and to challenge her thoughts }\end{array}$ \\
\hline \multirow[t]{4}{*}{$\begin{array}{l}\text { Phase } 3 \text { : A nascent sense } \\
\text { of agency }\end{array}$} & $\begin{array}{l}\text { - "I knew I would binge, because l'd got } \\
\text { that feeling }\end{array}$ & $\begin{array}{l}\text { Strengthen the patient's sense of agency by } \\
\text { focusing on the experiences when she } \\
\text { appeared to have a choice ("Yes, you binged } \\
\text { in the evening, but you said that you waited } \\
\text { for couple of hours, so you made that } \\
\text { happen, can we look into that a bit?). }\end{array}$ \\
\hline & & $\begin{array}{l}\text { - Validation of the patient's fear of losing } \\
\text { control. }\end{array}$ \\
\hline & & $\begin{array}{l}\text { - Discuss and practice methods that help the } \\
\text { patient tolerate possible heightened level of } \\
\text { anxiety due to behavioral changes. }\end{array}$ \\
\hline & & - Focus on success rather than failure \\
\hline \multirow[t]{3}{*}{$\begin{array}{l}\text { Phase 4: A wavering } \\
\text { sense of agency }\end{array}$} & $\begin{array}{l}\text { - I can 't do it anymore, It 's not the same" } \\
\text { (stopping eating as a way to control } \\
\text { herself) }\end{array}$ & $\begin{array}{l}\text { - Validate the patient's feeling of mourning } \\
\text { and help her relate to her emotions with } \\
\text { compassion and understanding. }\end{array}$ \\
\hline & & $\begin{array}{l}\text { - Remind the patient that most of the time she } \\
\text { "makes choices" in terms of the ED } \\
\text { symptoms. }\end{array}$ \\
\hline & & $\begin{array}{l}\text { - Focus on the patient's "agency talk" and feed } \\
\text { it back to the patient ("It sounds like you } \\
\text { stopped for a moment and made a decision } \\
\text { before you reacted...,what's your } \\
\text { experience?" }\end{array}$ \\
\hline $\begin{array}{l}\text { Phase 5: A strong sense } \\
\text { of agency }\end{array}$ & $\begin{array}{l}\text { - "It came into my mind that I could lose } \\
\text { weight when I got the feeling of being an } \\
\text { outsider. I knew that it was my own fear". }\end{array}$ & $\begin{array}{l}\text { - Normalize ED related thoughts-"this is your } \\
\text { mind's way of reacting to distress, which } \\
\text { does not mean that your behavioral } \\
\text { symptoms are conquering you. ED related } \\
\text { thoughts are not dangerous" [the fear of the } \\
\text { ED thoughts produces more stress than the } \\
\text { thoughts themselves]. }\end{array}$ \\
\hline
\end{tabular}


states. In short, this case study suggests that identifying a patient's primary phase of a sense of agency in relation to eating disorder symptoms can offer a new perspective on treatment, helping the therapist select methods that fit the patient's capacity for change at certain points in therapy.

Using the concept of agency might also have implications for developing integrative approaches to working with a patient with an eating disorder-increasing the likelihood that the patient would benefit from a treatment that is adjusted to her real capacities. It also may help in preventing negative encounters in treatment, when the patient's difficulties with complying with nutritional and exercise instructions are interpreted as lack of motivation.

This model could also be of use in the treatment of the restricting type of eating disorder. The patient's experience in the first phase of the agency would possibly be more in the direction of "false sense of agency" (see Table 1) instead of experiencing "no agency at all". The authors of this article hypothesize that within that phase, the experience and emotional themes would evolve over time from feelings of false control to feelings of incompetence, helplessness, and shame. The therapeutic tasks would, in that case, be to understand, accept, and validate the patient's positive experience of her symptoms, but at the same time listen and explore her conflicted and ambivalent experiences. Thus, the most important task for the therapist would be to allow both sides of the ambivalence to live within the therapeutic relationship and to reflect on them.

This model overlaps somewhat with cognitive-behavioral therapy for eating disorders (Fairburn, 2008). There is as a focus in both approaches on maladaptive thought processes and behaviors, as well as on psychoeducation. The main difference is that the current model focuses on painful emotional experiences and themes that arise in different phases of a patient's Mackrill (2009) and Wahlström and Seilonen (2016) s sense of agency. These experiences are often barriers to behavioral change.

There are certain limitations in this case study. First, there is no basis to generalize the findings regarding different phases of agency within the current case study to patients suffering from other types of eating disorders, such as restrictive anorexia nervosa or binge eating disorder. Further research in patients with these disorders is required to provide a better understanding of the differences in the sense of agency among patients with restrictive versus binge-purge eating disorders. Second, a sense of agency is expected to be experienced and handled differently in adolescent in comparison to adult patients with eating disorders; in this regard, too, cultural differences have to be taken into consideration. Finally, further research is required to better understand how the development of agency in relation to eating disorder symptoms is connected to overall mentalization capacity in these patients, and to the development of mentalization during treatment.

\section{REFERENCES}

Allen, J. G., \& Fonagy, P. (2008). Mentalizing in clinical practice. Washington, DC: American Psychiatric Publishing, Inc. Bandura, A. (1977). Toward a unifying theory of behavioral change. Psychological Review, 84, 191-215.

Barker, C., Pistrang, N., \& Elliott, R. (2002). Research methods in clinical psychology. An introduction for students and practitioners. New York, NY: John Wiley \& Sons.

Boswell, J. F., Nelson, D. L., Nordberg, S. S., McNeavey, A. A., \& Castonguay, L. G. (2010). Competency in integrative psychotherapy: Perspectives on training and supervision. . Psychotherapy, 47(1), 3-1.

Bruch, H. (1974). Eating disorders, Obesity, anorexia nervosa and the person within. London, England: Routledge.

Fairburn, C. (2008). Cognitive behavior therapy and eating disorders, The Guilford Press. New York, NY

Fairburn, C., Stice, E., Cooper, Z., Doll, H. A., Norman, C., \& O'Connor, M. E. (2003). Understanding persistence in bulimia nervosa: A 5-year naturalistic study. Journal of Consulting and Clinical Psychology, 71(1), 103-109.

Fonagy, P., \& Target, M. (1997). Attachment and reflective function: Their role in self- organization. Development and Psychopathology, 9(4), 679-700.

Fonagy, P., \& Bateman, P. (2012). Eating disorders. In A. Bateman, \& P. Fonagy (Eds.), Handbook of mentalizing in mental health practice (pp. 347-384). Washington, D. C: American Psychiatric Puhlishing, Inc.

Frank, G. K. (2015). Advances from neuroimaging studies in eating disorders. Pediatric Neuroimaging, 20(4), 391-400.

Gullestad, F. S., \& Wilberg, T. (2011). Change in reflective functioning during psychotherapy - A single case research. Psychotherapy Research, 21(1), 97-111. 
Hope, N. H., Wakefield, M. A., Northey, L., \& Chapman, A. L. (2018). The association between locus of control, emotion regulation and borderline personality disorder features. Personality and Mental Health, 12(3), 241-251.

Kögler, H. H. (2010). Recognition and the resurgence of intentional agency. Inquiry, 53(5), 450-469.

Linardon, J., Fairburn, C. G., Fitzsimmons-Craft, E. E., Wilfley, D. E., \& Brennan, L. (2017). The empirical status of the thirdwave behaviour therapies for the treatment of eating disorders: A systematic review. Clinical Psychological Review, 58, 125-140.

Mackrill, T. (2009). Constructing client agency in psychotherapy research. Journal of Humanistic Psychology, 49(2), $193-206$.

Markin, R. D. (2014). Toward a common identity for relationally oriented clinicians: A Place to hang one's hat. Psychotherapy, 51(3), 327-333.

Prochaska, J. O., \& DiClemente, C. C. (1982). Transtheoretical therapy: Toward a more integrative model of change. Psychotherapy: Theory, Research \&Practice, 19(3), 276-288.

Skårderud, F., \& Fonagy, P. (2012). Eating disorders. In A. Bateman, \& P. Fonagy (Eds.), Handbook of mentalizing in mental health practice (pp. 347-384). Washington, D. C: American Psychiatric Puhlishing, Inc.

Steinert, C., Munder, T., Rabung, S., Hoyer, J., \& Leichsenring, F. (2017). Psychodynamic therapy: As efficacious as other empirically supported treatments? A meta-analysis testing equivalence of outcomes. American Journal of Psychiatry, 174(10), 943-953.

Stice, E., Davis, K., Miller, N., \& Marti, N. C. (2008). Fasting increases risk for onset of binge eating and bulimic pathology: A 5-year prospective study. Journal of Abnormal Psychology, 117(4), 941-946.

Treasure, J., \& Schmidt, U. (2001). Ready, willing and able to change: Motivational aspects of the assessment and treatment of eating disorders. European Eating Disorders Review, 9(1), 4-18.

Treasure, J., \& Schmidt, U. (2008). Motivational interviewing in eating disorders. In H. Arkowitz, H. Westra, W. R. Miller, \& S. Rollnick (Eds.), Motivational Interviewing and the promotion of mental health (pp. 194-224). New York: Guilford Press.

Treasure, J., Stein, D., \& Maguire, S. (2015). Has the time come for a staging model to map the course of eating disorders from high risk to severe enduring illness? An examination of the evidence. Early Interventions in Psychiatry, 9(3), 173-184.

Treasure, J., Cardi, V., Leppanen, J., \& Turton, R. (2015). New treatment approaches for severe and enduring eating disorders. Physiology \& Behavior, 152(part B), 456-465.

Vitousek, K., \& Ewald, L. S. (1993). Self-representation in eating disorders: A cognitive perspective. In Z. Segal, \& S. Blatt (Eds.), The Self in emotional distress: Cognitive and Psychodynamic perspectives (pp. 221-257). New York, NY: Guilford.

Vitousek, K., \& Watson, S. (1998). Enhancing motivation for change in treatment-resistant eating disorders. Clinical Psychology Review, 18(4), 391-420.

Wahlström, J., \& Seilonen, M. -L. (2016). Displaying agency problems at the outset of psychotherapy. European Journal of Psychotherapy \& Counselling, 18(4), 333-348.

William, D., \& Lewitt, H. (2007). Principles for facilitating agency in psychotherapy. Psychotherapy Research, 17(1), 66-82.

How to cite this article: Kristmannsdottir G, Keski-Rahkonen A, and Kuusinen KL. Changes in the sense of agency: Implications for the psychotherapy of bulimia nervosa- A case study. J. Clin. Psychol. 2019;1-14. https://doi.org/10.1002/jclp.22787 